\title{
Schurr, Marc Carel, Gotische Architektur im mittleren Europa 1220-1340
}

Anne Adrian

\section{OpenEdition}

\section{Journals}

Édition électronique

URL : http://journals.openedition.org/ifha/2174

DOI : 10.4000/ifha. 2174

ISSN : 2198-8943

\section{Éditeur}

IFRA - Institut franco-allemand (sciences historiques et sociales)

Référence électronique

Anne Adrian, « Schurr, Marc Carel, Gotische Architektur im mittleren Europa 1220-1340 », Revue de l'IFHA [En ligne], Date de recension, mis en ligne le 01 janvier 2010, consulté le 22 septembre 2020. URL: http://journals.openedition.org/ifha/2174 ; DOI : https://doi.org/10.4000/ifha.2174

Ce document a été généré automatiquement le 22 septembre 2020

(CIFHA 


\title{
Schurr, Marc Carel, Gotische Architektur im mittleren Europa
}

\section{$1220-1340$}

\author{
Anne Adrian
}

Cet ouvrage très documenté ne s'assigne pas une description exhaustive de tous les édifices religieux construits ou reconstruits à l'époque gothique " de Metz à Vienne ", mais propose une sélection de ceux qui se distinguent par leur importance politique et artistique, constituant autant de jalons pour comprendre le développement et le rayonnement d'un style dans un contexte culturel commun. Le cadre de la "nation » est considéré comme inapproprié pour cette étude, au profit d'une identité et d'une histoire plus « européennes » de régions situées entre Rhin et Danube.

Trois parties aux titres très synthétiques semblent tracer une évolution qui ne se veut pas simplement linéaire mais souligne l'apport de chaque édifice inscrit dans un réseau d'influences et d'échanges : les débuts de la construction gothique dans l'Empire (1220-1250), l'apparition de nouveaux modèles (1250-1280), richesse et diversité (1280-1340). Dans la présentation de chaque édifice, l'auteur équilibre son propos entre l'examen des aspects archéologiques de la construction et l'analyse des formes qui confère à l'observation du monument le statut de source première.

En fin d'ouvrage, un catalogue de notices accompagnées de plans et de relevés et d'une bibliographie, établi par ordre alphabétique des édifices présentés dans le corps de l'ouvrage, complète cette approche riche de 49 édifices (d'Arnstadt à Xanten).

En les situant précisément dans leur contexte de construction, l'auteur souligne le rôle décisif de certains édifices dans la réception et la circulation du répertoire formel gothique dans l'Empire, comme la cathédrale de Toul dont le chœur, reconstruit après 1220 , regarde vers le modèle rémois tout en attestant la qualité de l'atelier local. L'apport technique et artistique de constructions comme la cathédrale de Metz (v. 1240) trouve une continuité dans des édifices-jalons comme la cathédrale de Cologne (chœur, v. 1248). 
M.C.S. recense avec précision les constructions qui se situent dans la mouvance de ces édifices-jalons (mouvance de Strasbourg, Marbourg, Naumbourg) et les échanges réguliers entretenus par exemple entre les ateliers de Bohême et d'Autriche dans les années 1250-1270 et ceux de centres artistiques situés plus à l'ouest comme Strasbourg, Metz et Cologne. Dans un certain nombre de cas (Toul, Metz, Cologne, Ratisbonne), la connaissance des commanditaires et de leurs intentions permet d'éclairer le contexte de ces échanges. Un autre intérêt de cette étude est l'observation de l'interaction entre le politique et les projets de constructions, depuis l'influence de grands personnages sur la diffusion d'un type architectural érigé en modèle jusqu'au rôle de légitimation politique joué par l'architecture.

Ainsi, une présentation à la fois détaillée et synthétique des édifices - fruit d'une étude archéologique et technique très avancée - et de leur situation à l'échelle d'une région et au-delà, constitue la richesse de cet ouvrage. L'auteur met en évidence leur participation à un processus innovant en dégageant leur spécificité par rapport au gothique français ou anglais.

Anne Adrian (Musées de Metz Métropole - La Cour d'Or) 